\title{
The metabolic response to spinal cord injury
}

\author{
Donna J Rodriguez, Edward C Benzel and Frederick W Clevenger*
}

Neurosurgery Division, Department of Surgery, University of New Mexico School of Medicine, ACC 2nd Floor, Albuquerque, New Mexico, 87131, USA

\begin{abstract}
The metabolic response to trauma, including neurotrauma in general, has been studied extensively, but the acute metabolic response to spinal cord injury (SCI) has not. Therefore, 12 patients with SCI are presented in whom intensive nutrition assessment and management were instituted immediately after injury. Nitrogen balance (NB), predicted energy expenditure (PEE), and actual energy expenditure (MEE) were calculated or measured in each patient. A persistent negative NB was observed in all but one of the 12 patients. The single patient who did not exhibit persistent negative NB (no positive NB from week 2 to week 4 in the face of appropriate feeding) had an incomplete myelopathy, thus implying that the degree of motor dysfunction correlates with the obligatory nature of the negative NB. The negative NB observed in several of the patients did not occur until the second or third post-injury week. In addition, calculations of PEE by successively multiplying the Harris-Benedict equation by an activity factor of 1.2 and then by a stress factor of 1.6, resulted in excessive feeding (as assessed by metabolic cart measurements; ie indirect calorimetry) in the majority of the patients. In all of the 11 patients with persistent negative NBs, protein administration in the amount of $2 \mathrm{~g} / \mathrm{k}$ of ideal body weight and aggressive caloric delivery did not alter the negative pattern of the NBs. Therefore, it is concluded that the negative NB following SCI is obligatory. Furthermore, the extent of SCI (extent of myelopathy or of neurological injury) correlates with the obligatory nature of the negative NB. In addition, the results from using the above method for estimating caloric requirements and the delayed manifestation of the negative NB may cause an additional tendency to acutely overfeed SCI patients. Therefore, eliminating the activity factor of 1.2 (due to the diminished activity arising from paralysis) and a diminution of the stress factor is recommended for initial PEE calculations. Serial metabolic cart (indirect calorimetry) measurements are recommended to accurately assess the patient's subsequent metabolic requirements.
\end{abstract}

Keywords: spinal cord injury; nitrogen balance; nutrition; metabolism; indirect calorimetry

\section{Introduction}

Traumatic spinal cord injury (SCI) is common, with substantial accompanying human suffering and monetary loss. SCI is often associated with injuries to other organ systems and is compounded by complications such as respiratory insufficienty and infection. Nutritional status affects both the incidence and significance of these complications. Therefore, it is prudent to understand how SCI affects substrate requirements and use.

The metabolic response to severe trauma is complex. Initially, elevations in urinary nitrogen losses and in energy expenditures are observed in patients without SCI. ${ }^{1,2}$ Resolution of this hypermetabolism, with or without aggressive nutrition

Correspondence: EC Benzel

*Deceased support, usually ensues within $1-3$ weeks. Nitrogen balance (NB) then normalizes (to zero) or becomes positive.

A delayed chronic phase that is characterized by an obligatory loss of lean body mass, a marked reduction in substrate use, and decreased metabolic activity has been observed and extensively studied in SCI. ${ }^{3-5}$ Although the chronic phase has been well described, the characteristics of the acute metabolic response to SCI are poorly understood. This response may, indeed, diverge significantly from that observed with non-SCI trauma.

An inability to establish a positive NB acutely after SCI, has been previously documented. This is despite a relative ability to do so in other groups of severely injured patients. ${ }^{6,7}$

Whereas, in non-spinally injured patients, the nitrogen balance is usually negative during the first 2 weeks following injury, in spinal injured patients it 
remains negative for a longer time frame; presumably due to the denervation of the lean muscle mass. The late peak of nitrogen loss occurs at a time when the energy expenditure is falling. Furthermore, it is unresponsive to high caloric and protein intake.

In an attempt to further characterize the metabolic aberrations that follow SCI and to establish the patients' tolerance and response to aggresssive nutrition support, 12 SCI patients were studied with respect to protein and caloric intake, nitrogen balance, and indirect calorimetry.

\section{Methods}

Twelve patients with acute SCI were treated with an aggressive approach to nutrition support at the University of New Mexico Medical Center. Upon admission, nutrition needs were calculated for each patient. Protein delivery was based on 2 grams protein/ kilogram of ideal body weight (IBW). ${ }^{8,9}$ (IBW for male: 106 pounds for the first 5 feet plus 6 pounds for every inch taller; IBW for female: 100 pounds for the first 5 feet plus 5 pounds for every inch taller). ${ }^{10}$ Basal energy expenditures (BEE) were estimated by the Harris-Benedict equation (weight in kilograms, height in centimeters, age in years) for both men and women:

Men (kcal/day):

$$
\mathrm{BEE}=66+(13.8 \times \mathrm{kg})+(5 \times \mathrm{cm})-(6.8 \times \text { age })
$$

Women (kcal/day) :

$$
\mathrm{BEE}=655+(9.6 \times \mathrm{kg})+(1.8 \times \mathrm{cm})-(4.7 \times \text { age })
$$

Predicted energy expenditures (PEE) were then calculated for each patient by multiplying individual BEE by 1.2 (an activity factor for bedrest) and then by 1.6 (an injury factor for major trauma): ${ }^{11}$

$$
\mathrm{PEE}=\mathrm{BEE} \times 1.2 \times 1.6
$$

Although this method of predicting energy expenditure may yield high values compared to other reports, ${ }^{2}$ it is used here because it is a documented standard. Therefore, an assessment of its accuracy is warranted.

Total nutrition support was delivered within $48 \mathrm{~h}$ of admission. Nutrition support (route determined by patient tolerance) was provided in amounts necessary to meet calculated protein and caloric needs. Parenteral nutrition support (total parenteral nutrition [TPN]) was converted to enteral nutrition per nasal-duodenal feeding (tube feeding [TF]) as early as patient gut function allowed. Subsequent changes in nutrient delivery were based on NB and indirect calorimetry (metabolic cart) measurements. These measurements allowed the determination of the actual measured energy expenditures (MEE) and the respiratory quotient (RQ).

Protein and calorie intakes, types of formulas, and formula tolerances were recorded on a daily basis. Twenty-four urinary urea nitrogen (UUN) specimens were collected on each patient only when protein and caloric intakes were meeting estimated needs, and repeated weekly or when dictated by clinical conditions.

Aliquots of each $24 \mathrm{~h}$ urine collection were assayed for their urea nitrogen contents by a standard enzymatic laboratory technique using the Beckman Astra (Beckman Instruments, Fullerton, California). NBs were then calculated using the following equation: ${ }^{12}$

$$
\mathrm{NB}=\frac{24 \mathrm{~h} \text { protein intake }}{6.25}-(24 \mathrm{~h} \mathrm{UUN}+4)
$$

where protein intake is measured in grams $(6.25$ is the conversion factor for calculating the nitrogen in a given amount of protein); $24 \mathrm{~h}$ UUN losses are added to an average amount of 4 grams of insensible (or nonurinary) nitrogen losses or 2 grams in the stool plus 2 grams from the skin.

Although some patients experienced diarrhea, NBs were calculated using the above NB equation due to reports that even in the face of diarrhea, stool losses of greater than 2 grams/day are uncommon. ${ }^{13}$

Indirect calorimetry was performed on both mechanically ventilated and spontaneously breathing patients with the Critical Care Monitor (CCM) metabolic cart (Medical Graphics Corporation, St. Paul, Minnesota). Patients were not in postabsorptive states, but received continuous feedings during the time that energy expenditures were measured. Only those studies were used that had fluctuations in $\mathrm{FIO}_{2}$ of less than $0.02 \%$ and which demonstrated steady state measurements. These metabolic cart studies were condutcted weekly when possible, but were not performed if inspired oxygen concentrations exceeded $60 \%$.

Data collection was discontinued when the patient began taking food orally or when elevations of blood urea nitrogen (or other manifestations of renal failure) intervened. These factors altered the NB data so that it was uninterpretable for study purposes. Thus, only the more ill patients were studied because oral caloric intake (a manifestation of recovery or relative good health) was a criteria for either exclusion from the study or to discontinue data collection. In addition, data was not collected if the patient was not receiving calories at a steady state during a given week (eg, intervening surgery or a transition from parenteral to enteral feeding). This, obviously, would also have resulted in erroneous data collection. Data was collected for at least 4 weeks or until the above criteria were met. Included in the study were only those patients who had at least two accurate weekly NBs and one metabolic cart calculation (indirect calorimetry) performed in the first 4 weeks after admission.

\section{Results}

Eleven patients were male and one was female. The mean age of the patient population was 32 years (range $21-77$ years). Six had cervical spine injuries and six 
had incurred thoracic spine injuries. None of the patients had cauda equina injuries. Ten patients suffered complete myelopathies (Benzel/Larson ${ }^{14,15}$ grade 1). Two patients suffered incomplete myelopathies and were classified as follows:

Patient 11 - Benzel/Larson grade 2 - motor complete myelopathy (ie, sensory sparing without motor function below the level of the injury).

Patient 12 - Benzel/Larson grade 5 - incomplete motor and sensory paralysis (ie, strong enough to walk with minimal assistance).

Table 1 presents the NB data. The empty spaces in Table 1 indicate that no data was collected. In these cases, either a steady state was not achieved, renal failure was ensuing, or oral intake prevented accurate assessment. Many of the patients had a positive NB during the first week following injury. Patient 2 (Table 1) received methylprednisolone as per the NASCIS-II protocol. ${ }^{16}$ This did not appear to affect the metabolic response to SCI adversely in this single patient.

Table 2 portrays the energy expenditure data collected on the patients presented here. During the week 1 and week 2 following injury, the MEE was lower than the PEE in the majority of the patients (except for patients 1, 7, and 10; Table 2).

Nutrition support was initiated within $48 \mathrm{~h}$ of admission. Selection of the appropriate access route

Table 1 Nitrogen balance in SCI patients

\begin{tabular}{|c|c|c|c|c|}
\hline $\begin{array}{l}\text { Patient } \\
\text { number }\end{array}$ & $\begin{array}{c}\text { Week 1 } \\
\text { Nitr In (grams) } \\
\text { UUN (grams)/UUN }+4 \\
\text { Balance }\end{array}$ & $\begin{array}{c}\text { Week } 2 \\
\text { Nitr In (grams) } \\
U U N(\text { grams }) / U U N+4 \\
\text { Balance }\end{array}$ & $\begin{array}{c}\text { Week } 3 \\
\text { Nitr In (grams) } \\
\text { UUN }(\text { grams }) / U U N+4 \\
\text { Balance }\end{array}$ & $\begin{array}{c}\text { Week } 4 \\
\text { Nitr In (grams) } \\
\text { UUN }(\text { grams }) / U U N+4 \\
\text { Balance }\end{array}$ \\
\hline \multicolumn{5}{|c|}{$\begin{array}{l}\text { Motor and sensory } \\
\text { Complete myelopathy }\end{array}$} \\
\hline 1 & $\begin{array}{c}18.2 \\
16.2 / 20.2 \\
-2.0\end{array}$ & $\begin{array}{c}21.4 \\
23.9 / 27.9 \\
-6.5\end{array}$ & - & $\begin{array}{c}23.4 \\
24.0 / 28.0 \\
-4.6\end{array}$ \\
\hline 2 & $\begin{array}{l}22.1 \\
21.1 / 25.1 \\
-3.0\end{array}$ & - & $\begin{array}{c}22.1 \\
21.1 / 25.1 \\
-3.0\end{array}$ & - \\
\hline 3 & $\begin{array}{c}22.1 \\
25.0 / 29.0 \\
-6.9\end{array}$ & - & $\begin{array}{l}16.0 \\
21.9 / 25.9 \\
-9.9\end{array}$ & $\begin{array}{c}21.8 \\
22.0 / 26.0 \\
-4.2\end{array}$ \\
\hline 4 & $\begin{array}{l}26.6 \\
24.1 / 28.1 \\
-1.5\end{array}$ & - & $\begin{array}{l}17.6 \\
27.6 / 31.6 \\
-14.0\end{array}$ & - \\
\hline 5 & $\begin{array}{c}24.0 \\
17.0 / 21.0 \\
+3.0\end{array}$ & - & $\begin{array}{l}15.4 \\
26.4 / 30.4 \\
-15.0\end{array}$ & - \\
\hline 6 & $\begin{array}{c}21.8 \\
15.0 / 19.0 \\
+2.8\end{array}$ & $\begin{array}{c}19.2 \\
28.2 / 32.2 \\
-13.0\end{array}$ & $\begin{array}{c}27.2 \\
28.9 / 32.9 \\
-5.7\end{array}$ & - \\
\hline 7 & $\begin{array}{c}23.2 \\
27.2 / 31.2 \\
-8.0\end{array}$ & $\begin{array}{l}25.0 \\
48.0 / 52.0 \\
-27.0\end{array}$ & - & - \\
\hline 8 & $\begin{array}{l}23.2 \\
12.4 / 16.4 \\
+6.8\end{array}$ & $\begin{array}{c}21.8 \\
28.8 / 32.8 \\
-11.0\end{array}$ & $\begin{array}{l}21.8 \\
24.0 / 28.0 \\
-6.2\end{array}$ & - \\
\hline 9 & - & $\begin{array}{l}25.4 \\
26.0 / 30.0 \\
-4.6\end{array}$ & - & - \\
\hline 10 & $\begin{array}{r}23.0 \\
0.0\end{array}$ & $\begin{aligned} & 19.2 \\
& 19.0 / 23.0 \\
&- 13.8\end{aligned}$ & $\begin{array}{l}26.9 \\
29.0 / 33.0 \\
-15.0\end{array}$ & $\begin{array}{c}- \\
37.9 / 41.9\end{array}$ \\
\hline Incompl & elopathy & & & \\
\hline 11 & - & $\begin{array}{l}24.0 \\
38.0 / 42.0 \\
-18.0\end{array}$ & $\begin{array}{l}28.8 \\
34.8 / 38.8 \\
-10.0\end{array}$ & - \\
\hline 12 & $\begin{array}{l}19.2 \\
14.0 / 18.0 \\
+1.2\end{array}$ & $\begin{array}{l}19.2 \\
14.0 / 18.0 \\
+1.2\end{array}$ & $\begin{array}{l}19.2 \\
23.0 / 27.2 \\
-8.0\end{array}$ & $\begin{array}{l}24.0 \\
19.0 / 21.0 \\
+3.0\end{array}$ \\
\hline
\end{tabular}


to administer nutrients was based on gut function. In 11 of the 12 patients, parenteral nutrition support was the first mode of therapy due to the presence of ileus. In the remaining patient, $\mathrm{TF}$ was the first mode of alimentation. The length of time that patients remained on TPN ranged from 4 to 33 days (mean 16 days). TPN was changed to TF in nine patients; and to oral diets in two patients. Conversion of TPN to $\mathrm{TF}$ was hindered by complications of diarrhea, abdominal distension and emesis in five patients. Incidence of $\mathrm{TF}$ complications was not related to choice of formula. TPN and TF goal rates were based on initial calculations of protein and caloric needs. Increases in intakes above initially estimated needs were made to assure that negative NBs were not due to unaccounted for hypermetabolic states.

\section{Discussion}

The injury-stress response (hypermetabolism and hypercatabolism) following major trauma has been well characterized physiologically. ${ }^{1,2,17}$ Dramatic increases occur in nitrogen excretion and total body protein catabolism, and in energy expenditure. Increased protein turnover, predominantly from skeletal muscle, also indicates that nitrogen require- ments are much greater than maintenance levels. Accelerated protein breakdown, which is detected by increased urinary nitrogen output, leads to a loss of lean muscle mass, organ failure, and death. Although substrate overload is a potential concern in acutely injured patients, current recommendations of 2 grams of protein/kilogram of IBW appear to be acceptable. ${ }^{8,9}$ It also eliminates any 'excuse' for an iatrogenic negative nitrogen balance. Energy requirements, that rarely exceed $200 \%$ of the basal energy expenditure, must also be met to minimize catabolism of lean body mass.

The metabolic response to neurotrauma, specifically, has been extensively studied. Management schemes for patients sustaining severe head trauma have been outlined. ${ }^{18}$ Information with regard to the metabolic response to SCI is somewhat less prolific and is centered about two time frames: the early and the delayed response to SCI. The earliest and most extensive work in this area pertains to the delayed metabolic response to SCI.

After acute SCI, a patient's early metabolic response is presumably influenced by the hypermetabolism related to the injury, as well as the decreased energy requirements due to the paralysis. During the first week following injury, many of the patients

Table 2 Measured energy expenditures in SCI patients

\begin{tabular}{|c|c|c|c|c|c|c|}
\hline $\begin{array}{l}\text { Patient } \\
\text { number }\end{array}$ & $\begin{array}{c}\text { Age/sex } \\
\text { injury* }\end{array}$ & $\begin{array}{c}P E E \\
k c a l / \text { day }\end{array}$ & $\begin{array}{c}\text { Week } 1 \\
M E E / R Q\end{array}$ & $\begin{array}{c}\text { Week } 2 \\
M E E / R Q\end{array}$ & $\begin{array}{c}\text { Week } 3 \\
M E E / R Q\end{array}$ & $\begin{array}{l}\text { Week } 4 \\
M E E / R Q\end{array}$ \\
\hline \multicolumn{7}{|c|}{ Motor and sensory } \\
\hline 1 & $\begin{array}{c}22 / \mathrm{F} \\
\mathrm{C} 3\end{array}$ & 2864 & - & $3500 / 0.67$ & - & $2621 / 0.73$ \\
\hline $2 * *$ & $\begin{array}{c}21 / \mathrm{M} \\
\mathrm{C} 5\end{array}$ & 3352 & $2696 / 0.83$ & $3625 / 0.79$ & - & - \\
\hline 3 & $\begin{array}{c}25 / \mathrm{M} \\
\mathrm{C} 4\end{array}$ & 3287 & $2149 / 0.62$ & - & - & $1827 / 1.1$ \\
\hline 4 & $\begin{array}{c}24 / \mathrm{M} \\
\mathrm{T} 3\end{array}$ & 3803 & $1539 / 1.0$ & - & - & - \\
\hline 5 & $\begin{array}{c}26 / \mathrm{M} \\
\mathrm{T} 3\end{array}$ & 3400 & $2557 / 1.07$ & - & - & - \\
\hline 6 & $\begin{array}{c}47 / \mathrm{M} \\
\mathrm{T} 12\end{array}$ & 3083 & $2338 / 0.55$ & $1775 / 0.76$ & - & - \\
\hline 7 & $\begin{array}{c}26 / \mathrm{M} \\
\mathrm{T} 6\end{array}$ & 3778 & $3793 / 0.94$ & - & - & - \\
\hline 8 & $\begin{array}{c}77 / \mathrm{M} \\
\mathrm{C} 3\end{array}$ & 2717 & $2411 / 0.74$ & $2312 / 0.87$ & - & $2163 / 0.76$ \\
\hline 9 & $\begin{array}{c}22 / \mathrm{M} \\
\mathrm{C} 5\end{array}$ & 3727 & - & $2217 / 1.2$ & - & - \\
\hline 10 & $\begin{array}{c}25 / \mathrm{M} \\
\mathrm{T} 7\end{array}$ & 3203 & $3874 / 0.83$ & - & $3460 / 0.89$ & - \\
\hline \multicolumn{7}{|c|}{ Incomplete mye lopathy } \\
\hline 11 & $\begin{array}{c}27 / \mathrm{M} \\
\mathrm{C} 7\end{array}$ & 4068 & $3225 / 0.79$ & $4987 / 0.75$ & $4500 / 0.88$ & - \\
\hline 12 & $\begin{array}{c}38 / \mathrm{M} \\
\mathrm{T} 10\end{array}$ & 2843 & - & $2352 / 0.81$ & - & $3431 / 0.91$ \\
\hline
\end{tabular}

*Injury $=$ lowest spinal level spared $(\text { Benzel/Larson SCI grade })^{3,4} . * *$ Patient received methylprednisolone ${ }^{5}$ 
presented here were observed to have a positive NB. This observation does not, most likely, reflect a true 'incorporation' of protein into body stores. It may, however, reflect a 'lagging behind' or a delay in actual losses of protein. The indirect calorimetry studies presented here demonstrated that during week 1 and week 2 following SCI, PEEs were greater than MEEs. It is probable that the activity factor of 1.2 used with these acute patients should be eliminated and the stress factor diminished when estimating initial energy requirements.

In studies related to the delayed long-term metabolic effects of SCI, a progressive loss of lean body $\operatorname{mass}^{19}$ and a reduction in energy expenditure have been observed. ${ }^{3-5}$ Despite more than adequate protein and caloric administration, nitrogen losses are not minimized and a negative NB ensues. ${ }^{6}$ It may take approximately a week for these obligatory protein losses to become manifest. Although measurement of total urinary nitrogen is a more accurate method of determining actual nitrogen losses, the data presented here does reflect striking changes in UUN and NB especially during week 2 and week 3 post-injury. For example, patient 7 had a net negative NB of 27 gram/ day despite a nitrogen intake of 25 gram/day. It was demonstrated that obligatory nitrogen losses after SCI persist for approximately 7 weeks.

In addition to the authors' findings, Kaufman et al have also reported marked negative NBs for 10 to 14 days after SCI. However, it was not specified by these investigators how protein needs were estimated or if these needs were being met at the time of NB determinations. $^{20}$ When Kolpek et al compared UUN excretions by seven acute SCI patients to seven head trauma patients, similar results were observed. In their SCI group, peak negative NB was observed during week 3 despite adequate delivery of predicted and measured calories. ${ }^{6,17}$

Several speculations have been made concerning the etiology of the obligatory negative NB. Bunker et al after comparing housebound elderly people to agematched active individuals, speculated that immobility led to wasting and breakdown of muscle protein. ${ }^{21}$ Dietrick et al also showed that during immobility an increase in nitrogen excretion and negative NBs occurred. A delay in development of the negative NB for 4 to 5 days was observed. ${ }^{22}$ From this data it is concluded that acute immobilization could, in part, be a cause of the acute post-injury increase in the nitrogen excretion observed in paralyzed patients, but that there is a delay of about one week before it becomes manifest.

Denervation atrophy has also been hypothesized as being responsible for this phenomenon. ${ }^{6}$ Notably, the patient with a motor and sensory incomplete myelopathy (Table 2) had a 'metabolic picture' not dissimilar to that previously observed with non-SCI patients with similar injuries (similar injury severity scores).

Decreased energy expenditures in comparison to standard predictivee formulas characterize the delayed metabolic response to SCI. Overfeeding in tetraplegic patients has been suggested by Agarwal et al when delivery of calories is based on the Harris-Benedict formula. ${ }^{3}$ Cox et al demonstrated a requirement of $22.7 \mathrm{kcal} / \mathrm{kg} /$ day for tetraplegic and $27.9 \mathrm{kcal} / \mathrm{kg} /$ day for paraplegic patients (45 to $90 \%$ of recommended calories based on various formulae). ${ }^{4}$ Kearns et al showed that when the Harris-Benedict equation was used, PEE exceeded MEE by a factor of 1.5 and subsequently suggested delivery of $80 \%$ of estimated caloric needs. ${ }^{5}$ In Kolpek's study, indirect calorimetry of SCI patients demonstrated marked reductions in REE, compared to the Harris-Benedict PEE. ${ }^{17}$ However, no mention of the use of stress or activity factors (if any) was made by the authors.

The use herein of PEEs that may be 'artificially high' is perhaps a self-fulfiling prophecy. In this situation the MEEs would essentially be ensured to be lower than their corresponding PEEs. This should be taken into account when considering the data presented here. In addition, if excessive caloric and protein replacement is employed because of the use of a high activity and stress factor, as may have been the case here, the MEEs may be expected to be artificially elevated because of increased energy expenditure and diet induced 'thermogenesis'. The observed MEEs in excess of $3000 \mathrm{kcal} /$ day may be explained, in part, by this phenomenon.

Finally, it is notable that the single patient with a motor complete myelopathy (Patient 1; Table 2) demonstrated a similar metabolic response to trauma as did the patients with complete myelopathies (Table $1)$; whereas, the patient with a motor incomplete myelopathy (Patient 2; Table 2) manifested a quite different metabolic response (a positive NB except for week 3). This implies, but does not confirm, that the extent of motor loss determines the metabolic response to SCI.

\section{Conclusions}

The regimen for treating acute SCI victims used in the patients presented herein is based on 2 grams protein/ $\mathrm{kg}$ ideal body weight and calories predicted by BEE times an activity factor of 1.2 and a stress factor of 1.6. It appears that these 'fudge factors' are too high, and that the elimination of an activity factor, and a diminution of the stress factor may provide more clinically appropriate information.

Additional adjustments are then based on indirect calorimetry measurements and calculations of the MEE. Relying on NB determinations to ascertain subsequent caloric and protein administration leads to improper feeding; most often overfeeding.

\section{References}

1 Fry DE, Borzotta AP. Options in nutritional support of the surgical patient. Prob Gen Surg 1987; 4: 427-440. 
2 Kinney JM, Duke JH Jr, Long CL et al. Tissue fuel and weight loss after injury. J Clin Patho 1970; 14: 65-72.

3 Agarwal N, Lee BY, Corcoran L et al. Energy expenditure in quadriplegic patients. JPEN 1984; 8: 98 (abstr).

4 Cox SAR, Weiss SM, Posuniak EA et al. Energy expenditure after spinal cord injury: An evaluation of stable rehabilitating patients. J Trauma 1985; 25: 419-423.

5 Kearns PJ, Pipp TL, Quirk M, Campolo M. Nutritional requirements in quadriplegics. JPEN 1982; 6: 577 (abstr).

6 Rodriguez DJ, Clevenger FW, Osler TM et al. Obligatory negative nitrogen balance following spinal cord injury. JPEN 1991; 15: $319-322$.

7 Rodriguez DJ, Clevenger FW, Osler TM et al. Correlation between injury severity and subsequent caloric needs: plea for a fixed stress factor. JPEN 1990; 14 (1): 15S.

8 Shronts EP. Nutrition Support in Metabolic Stress. In: Shronts EP, (ed). Nutrition Support Core Curriculum, American Society of Parenteral and Enteral Nutrition 1989; 199-211.

9 Clevenger, FW, Rodriguez DJ, Demarest GB et al. Protein and energy tolerance by stressed geriatric patients. J Surg Res 1992; 52: $135-139$.

10 American Diabetic Association, and American Dietetic Association. A guide for professionals: The effective application of exchange lists for meal planning. New York: 1977; 17.

11 Long CL, Schaffel N, Geiger JW et al. Metabolic response to injury and illness: estimation of energy and protein needs from indirect calorimetry and nitrogen balance. JPEN 1979; 3: 452 456.

12 McKenzie TA, Clark NG, Bistrian BR et al. A simple method for estimation of nitrogen balance in hospitalized patients: A review and supporting data for a previously proposed technique. $\mathrm{Am} \mathrm{C}$ Nutr 1985; 4: 575-581.
13 Daley BJ, Bistrian BR. Nutritional assessment. In: Zaloga, GP, (ed). Nutrition in Critical Care. Mosby-Year Book Inc 1994: New York: $9-33$.

14 Benzel EC, Larson SJ. Functional recovery after decompressive operation for thoracic and lumbar spine fractures. Neurosurgery 1986; 19: $772-778$

15 Benzel EC, Larson SJ. Functional recovery after decompressive spine operation for cervical spine fractures. Neurosurgery 1987; 20: $742-746$

16 Brakcen MB, Shephard MJ, Collins WF. A randomized, controlled trial of methylprednisolone or naloxone in the treatment of acute spinal-cord injury. NEJM 1990; 322: $1405-$ 1411.

17 Kolpek JH, Ott LG, Record KE et al. Comparison of urinary urea nitrogen excretion and measured energy expenditure in spinal cord injury and nonsteroid-treated severe head trauma patients. JPEN 1989; 13: $277-280$.

18 Young B, Ott L, Phillips R, McClain C. Metabolic management of the patient with head injury. Neurosurg Clinic North Am 1991; 2: $301-320$.

19 Greenway RM, Houser HP, Lindan O. Long term changes in gross body composition of paraplegic and quadriplegic patients. Paraplegia 1970; 7: $301-318$.

20 Kaufman HH, Rowlands BJ, Stein DK et al. General metabolism in patients with acute paraplegia and quadriplegia. Neurosurgery 1985; 16: $309-313$.

21 Bunker VW, Lawson MS, Stansfield MF et al. Nitrogen balance studies in apparently healthy elderly people and those who are housebound. Brit J Nut 1987; 57: 211 -221.

22 Dietrick JE, Whedon GD, Shorr E. Effects of immobilization upon various metabolic and physiologic functions of normal men. Ann J Med 1948; 4: 3-36. 